\title{
Author Correction: Unifying scrambling, thermalization and entanglement through measurement of fidelity out-of-time-order correlators in the Dicke model
}

\author{
R.J. Lewis-Swan ${ }^{1,2,4}$, A. Safavi-Naini, ${ }^{1,2,4}$, J.J. Bollinger ${ }^{3} \&$ A.M. Rey ${ }^{1,2 \star}$
}

Correction to: Nature Communications https://doi.org/10.1038/s41467-019-09436-y, published online 5 April 2019.

The original version of this Article omitted references to previous work in 'Fine, B. V., Elsayed, T. A., Kropf, C. M. \& de Wijn, A. S. Absence of exponential sensitivity to small perturbations in nonintegrable systems of spins 1/2. Phys. Rev. E 89, 012923 (2014)' and 'Elsayed, T. A. \& Fine, B. V. Sensitivity to small perturbations in systems of large quantum spins. Phys. Scr. 2015, 014011 (2015)'. These have been added as references 64 and 65 at the end of the penultimate sentence of the last paragraph of the 'Connections between scrambling dynamics and chaos' section of the Results: 'A similar factor of two relating the classical and quantum exponents has previously been observed in refs. $37,47,64,65$.' This has been corrected in the PDF and HTML versions of the Article.

Published online: 29 October 2019

\footnotetext{
c. reproduction in any medium or format, as long as you give appropriate credit to the original author(s) and the source, provide a link to the Creative Commons license, and indicate if changes were made. The images or other third party material in this article are included in the article's Creative Commons license, unless indicated otherwise in a credit line to the material. If material is not included in the article's Creative Commons license and your intended use is not permitted by statutory regulation or exceeds the permitted use,
} you will need to obtain permission directly from the copyright holder. To view a copy of this license, visit http://creativecommons.org/licenses/by/4.0/.

This is a U.S. government work and not under copyright protection in the U.S.; foreign copyright protection may apply 2019

\footnotetext{
${ }^{1}$ JILA, NIST and Department of Physics, University of Colorado, Boulder, CO 80309, USA. ${ }^{2}$ Center for Theory of Quantum Matter, University of Colorado, Boulder, CO 80309, USA. ${ }^{3}$ NIST, Boulder, CO 80305, USA. ${ }^{4}$ These authors contributed equally: R. J. Lewis-Swan, A. Safavi-Naini. *email: arey@jilau1.colorado.edu
} 